\title{
An Evaluation of the Mentoral Support Programme of Directorate of Staff Development
}

\author{
TasleemUllah* \\ SaleemUllah Jundran**
}

\begin{abstract}
It was an impact assessment study that was conducted to assess the impact of District Teacher Educators (DTE) mentoral support upon Primary School Teachers (PST) professional progress in Punjab. The Punjab Government's Continuous Professional Development (CPD) Program had been initiated through Directorate of Staff Development (DSD). Five years have passed since the start of this program. High expenditure was expected to be consumed for this task. Its effectiveness or the impact of this program needed to be assessed. Thus, the objectives were to assess the PSTs professional progress in the eight areas of mentoral support program, in M.B.D in district. The Questionnaire and Structured-Interview were taken as instruments. Data was hereby analyzed through percentage measure and Chi-square test. The sample consisted of two types of population. It was based upon 120 PSTs and 40 Heads of Secondary / Higher Secondary Schools working as Cluster Training and Support Centre (CTSC) Heads. Conclusions indicated that PSTs were satisfied about their professional progress acquired through DTEs. However, CTSC Heads were not found satisfied about the impact of DSD's mentoring program.
\end{abstract}

Keywords: DTE-District Teacher Educator, PST-Primary School Teacher, CPD-Continuous Professional Development, CTSC-Cluster Training \& Support Centre, Mentoral Support, Professional Progress.

*M.Phil Education, MUL. Email address: tujundran1@gmail.com

** Senior Headmaster / Cluster Training and Support Centre Head, Govt. High School Dhunni Klan (M.B.Din). Email address: sujundran66@gmail.com . 


\section{Introduction}

The professional development of teachers both at pre-service and in-service level is the need of hour. The professional development begins with in-service training and continues throughout the career (Saeed, 2000). Training is a sort of mentoring. Shukla (2005) defines mentoring as the step in which an experienced colleague is deputed to an inexperienced individual and help in a training. Ladd (2007) notes that many developed countries have been using formal mentoring programmes as a way to improve new teachers' chances of success. Paris (2010) has noted that Australia was finding teacher introduction poor and attrition rates were endemic in many States. Thus, mentoring was advocated as an important mechanism for countering this problem. Punjab Government's Continuous Professional Development Programme has been initiated on the behalf of DSD. For this purpose, DTEs have been recruited in three phases across the Punjab in all districts.(Directorate of Staff Development, 2007). Five years have passed since the start of this programme. High expenditure is going to be consumed for this task. Its effectiveness or the impact of this programme needs to be assessed.

The purpose of this study was to find out the Impact of District Teacher Educators Mentoral Support upon the Professional Progress of Primary School Teachers (Mentees).

\section{Objectives of the Study}

The Directorate of Staff Development has delineated eight areas of mentoral support program. Thus, there were following eight objectives of the study:

1. To analyze the impact of DTEs mentoral support upon mentees follow-up of ta'leemi calendar;

2. To assess the impact of DTEs mentoral support upon the mentees skill for the preparation of lesson plan;

3. To find out the mentees involvement in activity based learning;

4. To investigate the mentees skill in using support material;

5. To determine the mentees interaction with the majority of students;

6. To analyze the mentees skill to manage the class room;

7. To evaluate the mentees skill for students assessment;

8. To evaluate the mentees skill to assign meaningful home work to the students. 


\section{Review of the Related Literature}

The review section discusses the definitions of Mentor, Mentee, and District Teacher Educator, the concept of mentoral support programme and professional progress. It also discusses the introduction and implementation of mentoral programme in district Mandi Baha-ul-Din.

\section{Initiative of Mentoral Programme for Primary School Teachers in Mandi Baha-ul-Din District}

District Mandi Baha-ul-Din has found its name label from the town headquarters. A Gondal Jat Chief Bahauddin established a settlement namely PindiBahauddin in 1506 after his migration from Pindi Shah Jahanian to this area (District Courts Mandi Baha-ul-Din,). District Mandi Baha-ul-Din has three tehsils, i.e., Phalia, Malakwal, and Mandi Baha-ul-Din. Other important towns of M.B.Din district are Chillianwala, DhokKasib, Helan, Mangat, Qadir Abad, Mong, Wasu, Khuthiala Sheikhan and Bherowal. Formerly, it was a tehsil of District Gujrat. Punjabi is the major language of Mandi Baha-ul-Din. Nearby famous cities are Jehlum, Gujrat, Hafizabad, and Sargodha. Major tribes in Mandi Baha-ul-Din are Jat, Gujar, Rajpot, Syed, Arain, and Mughal. (Mandi Baha ul Din District, 2010). This district was inducted in the first phase of Punjab Government's mentoring programme. This District has three tehsils,i.e., Phalia, Malakwal and Mandi Baha-ul-Din. There have been established 40 Cluster Training and Support Centres in district Mandi Baha-ul-Din. Each Cluster Training and Support Centre, primarily, functions with the help of 02 DTEs, one Cluster Training and Support Centre Head and available Primary School Teachers (PSTs) appointed within its area.

Messurier (2012) says that mentoring is a significant and beneficial effect on the style of another person. It is a result of one-on-one contact.

Messurier (2012) adds that a mentor offers knowledge insight, perception, or wisdom that is useful to the other person. Shea notes as cited in Messurier (2012) that a mentor is described as a coach too. The DTEs conduct in-service short training courses for Primary School Teachers in their respective cluster centres from time to time. Reddy (2004) takes profession as an occupation based upon specialized study training. Its purpose is to supply skilled service or advice to others. 


\section{Evaluating Mentoring Programme: Rationale, Procedure and Significance}

According to Rossi (2004), of all the technically evaluation tasks, impact assessment is the most challenging. The evaluation design that has the best chance of detecting programme specific impact is the controlled randomized experiment. Mertens (2010) maintains the essential standards for evaluation credibility:
i. Feasibility
iv. Utility
ii. Propriety
v. Meta-evaluation.

Khawaja (2001) says about the characteristics of programme evaluation that evaluation should be realistic and relevant to decisionmaking. It is in the context of expectation or objectives, and assumption. It is supported by quantitative analysis. It is continuous and forwardlooking.

Corsini (1987) writes that programme evaluation is most typically applied to sponsored activities implemented through an identifiable organizational structure with designated staff, appropriate facilities, defined budget, and so forth. Programme evaluation might be applied to any such programme through in practice. Its domain has been almost exclusively human service programme. Agochiya (2009) reports that first stage is pre-training evaluation, second is ongoing evaluation, third is end programme evaluation and the best is post training evaluation. Thus the current study is related to ongoing evaluation study.

\section{Research Methodology}

It was both descriptive and survey type research. It was also an evaluative research. Its purpose was impact assessment of Directorate of Staff Development's ongoing mentoral support programme.

\section{Population}

It was limited to one District of Punjab Province. This District was inducted in the first phase of Punjab Government's Mentoring Programme. Its population was based upon:

1. All District Teacher Educators working in Mandi Bahauddin district.

2. All Primary Schools Teacher (PSTs) male and female working in public schools in Mandi Bahauddin district. 
3. All Cluster Training and Support Centre (CTSC) Heads working as Headmaster, Senior Headmaster and Principal in public sector in Mandi Bahauddin district.

\section{Sampling in the Study}

District Mandi Baha-ud-Din had three tehsils,i.e., Phalia, Malakwal and Mandi Baha-ud-Din. There were working 40 CTSCs in Mandi Baha-ud-Din district. Out of 40 CTSCs, 16 were in Tehsil Phalia, 10 in Tehsil Malakwal and 14 in Tehsil Mandi Baha-ud-Din.

One Cluster Training and Support Centre from each one Tehsil, area-wise, situated in the centre was chosen systematically. Forty CTSC Heads were involved here. Accordingly, CTSC Govt. High School Bherowal from Tehsil Phalia, CTSC Govt. High School MianaGondal from Tehsil Malkwal and CTSC Govt. High School Khuthiala Sheikhan from Tehsil M.B.Din were identified hereby.

The sample was based upon:

i. $\quad 40$ PSTs (Mentee Teachers) from each Tehsil.

ii. $\quad$ All CTSC Heads of 40 CTSCs.

\section{Mode of Data Collection}

The principal researcher himself delivered Questionnaire to all (PSTs) on the occasion of their Professional Development Days training. Their presence was definite on their respective PD Day training. Again, the researcher himself collected all filled in Questionnaires from the participants. Questionnaire was meant for PSTs. Structured Interview was meant for CTSC Heads. Structured Interview sheets were conveyed to CTSC Heads through Pakistan Post. Self-addressed postage stamp affixed envelopes were also conveyed along with it.

\section{Instruments of Data Collection}

It was a descriptive survey research. Therefore, questionnaire and structured interview were used as instruments here. These were relevant tools. 


\section{Construction of Questionnaire}

Questionnaire was related to the eight areas of mentoral Support. Each area was sub-divided into five more items. Mentoring progress related to each area's-sub item was noted down in five options or choices reflected as under:

1. Very Much

2. Much

3. Less

4. Very Less

5. No

Questionnaire consisted of forty questions. Items related to each area were as under:

\section{Area 1 Ta’leemi calendar}

1. Availability of Ta'leemi Calendar;

2. Availability of revised Ta'leemi Calendar;

3. Availability of guidance about the use of Ta'leemi Calendar;

4. Usage of Ta'leemi Calendar by Primary School Teachers;

5. Increase in PSTs professional skill by the use of Ta'leemi Calendar.

\section{Area 2 Lesson planning}

1. Availability of lesson plan;

2. Effectiveness of lesson plan in view of local requirement;

3. DTEs guidance about the preparation of lesson plan;

4. Improvement in teaching process through lesson plan;

5. Improvement in professional skill through usage of lesson plan.

\section{Area 3 Activity based learning}

1. DTEs guidance about Activity Based Learning;

2. Usage of stories and examples in teaching process;

3. Usage of Activity Based Learning Method during teaching;

4. Satisfaction about the activities given in BFM;

5. Improvement in professional skill through usage of activities. 
Area 4 Use of A.V. Aids.

1. Availability of A.V. Aids. in class room;

2. DTEs Guidance about the usage of low cast material;

3. Usage of A.V. Aids during teaching process;

4. Improvement in teaching process through usage of A.V. Aids;

5. Improvement in professional skill through usage of A.V.Aids.

\section{Area 5 Interaction with students.}

1. DTEs guidance about skilful interaction with students;

2. Skill improvement for interaction with students in large classes;

3. Teaching effectiveness in the light of DTEs guidance;

4. Improvement in students' performance through (teacher) interaction with them;

5. Improvement in teachers' professional skill through interaction with students.

\section{Area 6 Management of class rooms.}

1. Availability of DTEs guidance about class room management techniques;

2. Success in specific management for specific class room activities ;

3. Improvement in class-room management through DTEs guidance ;

4. Improvement in teaching process through better class room management;

5. Increase in professional skill through class room management.

\section{Area 7 Evaluation of students.}

1. Availability of DTEs guidance about students' assessment;

2. Availability of DTEs guidance about test item development techniques;

3. Teacher practice about the assessment of students' performance;

4. Increase in students' performance through assessment;

5. Increase in professional skill through students' assessment.

\section{Area 8 Home work.}

1. Availability of DTEs guidance about the assignment of home work;

2. Practice of checking students' home work on regular basis;

3. Practice of regular error correction during checking of home work; 
4. Increase in students' performance through home work;

5. Improvement in professional skill through checking of students' home work.

Questionnaire was pertinent to the eight areas of Mentoral Support. Each area was sub-divided into five more items. Mentoring progress pertinent to each area's sub item was noted down in five options or choices given as under:
6. Very Much
7. Much
8. Less
9. Very Less
10. No

\section{Pretesting of the Questionnaire}

Before distributing the Questionnaire to the participants, it was tried out in a pilot study. A focus group of thoughtful and critical individuals similar to the research participants was chosen. The copies of the Questionnaire were distributed among this focus group to get information about the deficiencies and improvements about the theme and diction of Question statements. In the light of suggestions provided by this group, Question-statements were further simplified and briefed. One of the participants of this group expressed her view that anonymity and confidentiality of the information provided by PSTs must be promised. These suggestions helped the Principal researcher in ensuring the content validity of the Questionnaire.

\section{Construction of Structured Interview}

Structured Interview was planned for seeking feedback response from CTSC Heads about the DSD's Mentoral Support Programme. It had four close-ended questions and one open-ended question. The close ended questions were related to impact assessment of this programme and open ended question, further sub-divided into five parts, was related to CTSC Heads proposals for the betterment of this programme. Thus, Structured Interview related to DTEs professional progress (sub-divided in to four questions and five required suggestions) was to be wrought with CTSC Heads responses about: 
1. Satisfaction about the effectiveness of mentoral programme of PSTs professional development ;

2. Increase in PSTs professional development through Mentoral Support Programme;

3. Satisfaction about DTEs professional performance ;

4. Perceptions about the overall standard of DSD's Mentoral Programme

\section{Pretesting of the Interview}

As with the Questionnaire, a small focus group was involved to refine interview Question-statements. Three CTSC Heads (Heads of Cluster, Training and Support Centre) were consulted for this purpose. One assessment expert/ statistician (Senior Subject Specialists Statistics) was also consulted to determine whether the resulting data can be quantified and analyzed in the manner intended.

\section{Data Collection, Analysis and Interpretation}

Data analysis was based on information received from the responses of PSTs and CTSC Heads. These responses were related to different areas and different categories. These responses were collected through following instruments:

(i) Questionnaire (QPSTs)

(ii) Interview (ICTSCHs)

Questionnaire was got filled in by the Primary School Teachers (PSTs). Structured interview was conducted with the CTSC Heads. Data was collected into two phases. The first phase of data was related to PSTs. The second phase of data was related to CTSC Heads.

\section{First Phase of the Study}

Analysis of Data through Chi-square Test in case of Questionnaire The detail of Data Tables is as under: 
Table1 
Table 2 
Table 3 
Table 4 
Table 5 
Table 6 
Table 7 
Table 8 


\section{Analysis of data through chi-square test}

Chi-Square, symbolized as $\mathrm{x}^{2}$ is a nonparametric test of significance. It is appropriate when the data are in the form of frequency counts or percentages and proportions that can be converted into frequencies. Two or more mutually exclusive categories are required in this test.

Hence, according to the nature of data acquired in this study, it is the most suitable statistical test for assessing the "Impact of District Teacher Educators Mentoring Support upon Primary School Teachers Professional progress in District Mandi-Baha-ul-Din”. The data tables already developed for percentage measure have been re-designed here according to the information required for application of this test. Its detail is as under:

\section{Null Hypothesis $=\mathbf{H}_{0}$}

DTEs mentoral support for PSTs professional progress is not effective in District M.B.Din.

\section{Alternative Hypothesis $=\mathbf{H}_{1}$}

DTEs mentoral support for PSTs professional progress is effective in District M.B.Din.

Table 9

Total Frequency Observed Response of PSTs about DTEs Mentoring Programme in District M.B.Din (Area 1 to 8)

\begin{tabular}{lccccccc}
\hline Area Number & Yes & No & V.Less & Less & Much & V .much & Total \\
\hline 1. Ta'leemi Calendar & 197 & 46 & 1 & 30 & 209 & 117 & 600 \\
2.Lesson Plan & 204 & 38 & 4 & 32 & 227 & 95 & 600 \\
3.Activity Based Learning & & 9 & 5 & 52 & 338 & 196 & 600 \\
4.Use of Support Material & & 23 & 21 & 86 & 324 & 146 & 600 \\
5.Interaction with Students & & 6 & 7 & 66 & 367 & 154 & 600 \\
6.Management of & & 7 & 7 & 37 & 348 & 201 & 600 \\
Classroom & & 6 & 8 & 37 & 376 & 173 & 600 \\
7.Assessment of Students & & 2 & 6 & 37 & 351 & 201 & 600 \\
8.Home Work & 401 & 137 & 59 & 377 & 2540 & 1286 & 4800 \\
Total & & & & & & &
\end{tabular}

Note: Individually, Area-wise Frequency observed can be seen from this Table 
Table 10

Total Frequency Expected (Fe) Response of PSTs about DTEs Mentoring Programme in District M.B.Din (Area 1 - 8)

\begin{tabular}{cccccccc}
\hline $\begin{array}{c}\text { Area } \\
\text { No. }\end{array}$ & Yes & No & V. less & Less & Much & V.Much & $\begin{array}{c}\text { Total } \\
(\mathrm{Fe})\end{array}$ \\
\hline 1 & 50.125 & 17.125 & 7.375 & 47.125 & 317.50 & 160.75 & 600 \\
2 & 50.125 & 17.125 & 7.375 & 47.125 & 317.50 & 160.75 & 600 \\
3 & 50.125 & 17.125 & 7.375 & 47.125 & 317.50 & 160.75 & 600 \\
4 & 50.125 & 17.125 & 7.375 & 47.125 & 317.50 & 160.75 & 600 \\
5 & 50.125 & 17.125 & 7.375 & 47.125 & 317.50 & 160.75 & 600 \\
6 & 50.125 & 17.125 & 7.375 & 47.125 & 317.50 & 160.75 & 600 \\
7 & 50.125 & 17.125 & 7.375 & 47.125 & 317.50 & 160.75 & 600 \\
8 & 50.125 & 17.125 & 7.375 & 47.125 & 317.50 & 160.75 & 600 \\
Total & 401 & 137 & 59 & 377 & 2540 & 1286 & 4800 \\
\hline
\end{tabular}

Note: This Table shows frequency expected of PSTs response about Mentoring Programme.

\section{Null Hypothesis $=\mathbf{H}_{\mathbf{0}}$}

DTEs mentoral support for PSTs professional progress is not effective in District M.B.Din.

\section{Alternative Hypothesis $=\mathbf{H}_{1}$}

DTEs mentoral support for PSTs professional progress is effective in District M.B.Din.

DTEs mentoral support for PSTs professional progress is not effective in District M.B.Din.

\section{Alternative Hypothesis $=\mathbf{H}_{1}$}

DTEs mentoral support for PSTs professional progress is effective in District M.B.Din.

Alternative Hypothesis has been accepted for the mentoral support for Primary School Teachers. 


\section{Second Phase of the Study}

Structured interview for CTSC heads:

\section{Delivery and Collection}

Structured Interview Sheets were delivered and received to 40 CTSC Heads through Pakistan Post.

The analysis of CTSC Heads responses about the impact of DTEs Mentoring Support upon the professional progress of PSTs has been presented below: 


\section{Analysis of data through Chi-square test}

Its detail is as under:

Table 12

Frequency Observed Questionnaires Response about CTSC Heads perception of Mentoral Support Programme in District M.B.Din

\begin{tabular}{lllllllllll}
\hline $\begin{array}{l}\text { Question } \\
\text { No }\end{array}$ & V.Less & Less & No & Much & V.Much & Best & Good & Fair & Weak & Total \\
\hline 01 & 6 & 13 & 5 & 12 & 4 & - & - & - & - & 40 \\
02 & 5 & 20 & 3 & 10 & 2 & - & - & - & - & 40 \\
03 & 3 & 14 & 4 & 15 & 4 & - & - & - & - & 40 \\
04 & - & - & - & - & - & 6 & 8 & 22 & 4 & 40 \\
Total & 14 & 47 & 12 & 37 & 10 & 6 & 8 & 22 & 4 & 160 \\
\hline
\end{tabular}

Note: The statements of the Qs. can be seen from the captions of the Table 3.

Table 13

Frequency Observed Response of CTSC Heads about Mentoral Support Programme in District M.B.Din

\begin{tabular}{lcccccc}
\hline Q.No & V.Less & Less+Fair & Not+Week & Much+Good & V.Much+Best & Total \\
\hline 01 & 6 & 13 & 5 & 12 & 4 & 40 \\
02 & 5 & 20 & 3 & 10 & 2 & 40 \\
03 & 4 & 14 & 4 & 15 & 4 & 40 \\
04 & - & 22 & 4 & 8 & 6 & 40 \\
Total & 14 & 69 & 16 & 45 & 16 & 160 \\
\hline
\end{tabular}

Note: The statements of the Qs. can be seen from the captions of the Table 4.

Table 14

Frequency Expected Response of CTSC Heads about Mentoring Support Programme in District M.B.Din.

\begin{tabular}{lrrccc}
\hline Q.No & V.Less & Less+fair & Not+week & Much+Good & V.Much+Best \\
\hline 01 & 3.50 & 17.25 & 4 & 11.25 & 4 \\
02 & 3.50 & 17.25 & 4 & 11.25 & 4 \\
03 & 3.50 & 17.25 & 4 & 11.25 & 4 \\
04 & - & 17.25 & 4 & 11.25 & 4 \\
\hline
\end{tabular}

Note: The statements of the Qs. can be seen from the captions of the Table 5. 
Table7

Question-wise Response of CTSC Heads about DTEs Mentoring Support Reflected in Frequency Observed and Expected According to i.e.,

\begin{tabular}{lccc}
\hline $\begin{array}{l}\text { Responses Item- } \\
\text { wise/ Area wise }\end{array}$ & $\begin{array}{c}\text { Frequency } \\
\text { Observed }\end{array}$ & $\begin{array}{c}\text { Frequency } \\
\text { Expected }\end{array}$ & $\frac{\left(\mathrm{f}_{0}-\mathrm{fe}\right)^{2}}{\mathrm{fe}}$ \\
\hline 1 & 6 & 3.50 & 1.79 \\
2 & 5 & 3.50 & 0.64 \\
3 & 3 & 3.50 & 0.07 \\
4 & 0 & 3.50 & 3.50 \\
5 & 13 & 17.25 & 1.05 \\
7 & 14 & 17.25 & 0.61 \\
8 & 22 & 17.25 & 1.30 \\
9 & 5 & 4 & 0.25 \\
10 & 3 & 4 & 0.25 \\
11 & 4 & 4 & 0.25 \\
12 & 4 & 4 & 0 \\
13 & 12 & 11.25 & 0.05 \\
15 & 15 & 11.25 & 1.25 \\
16 & 8 & 11.25 & 0.94 \\
17 & 4 & 4 & 0.00 \\
18 & 2 & 4 & 1.00 \\
19 & 4 & 4 & 0.00 \\
20 & 6 & 4 & 1.00 \\
& & & 14.28 \\
\hline
\end{tabular}

Note: The aggregate of values given in the last column indicates the value of Chi-square (x)2 ,i.e., $\mathrm{x} 2$

Null Hypothesis $=\mathrm{H}_{0}$

CTSC Heads were not satisfied about DTEs Mentoring Support Programme in District M.B.Din.

Alternative Hypothesis $=\mathrm{H}_{1}$

CTSC Heads were satisfied about DTEs Mentoring Support Programme in District M.B.Din.

It shows that CTSC Heads were not found satisfied about the Impact of District Teacher Educators Mentoring Support upon Primary School Teachers Professional Progress in District Manid Baha-ul-Din. Thus, Null Hypothesis has been accepted. 


\section{Findings of Study}

The study was pertinent to the impact of District Teacher Educators Mentoral Support upon Professional Progress of Primary School Teachers in District Mandi Baha-ul-Din have been given below.

\section{Phase 1}

Primary School Teachers Feedback about the Impact of District Teacher Educators Mentoral Support Programme

\section{Area No. 1 Ta'leemi Calendar}

Availability of Ta'leemi Calendar

1. $99 \%$ of PSTs replied that Ta'leemi calendar was available to them.

2. $1 \%$ of PSTs replied that Ta'leemi calendar was not available to them.

\section{Area No. 2 Lesson plan}

\section{Availability of lesson plan}

1. $99 \%$ of PSTs replied that Lesson plan was available to them.

2. $4 \%$ of PSTs replied that Lesson plan was not available to them.

\section{Area No.3 Activity based learning}

\section{DTEs Guidance about Activity based learning}

1. Forty-four percent of PSTs replied that DTEs very much guidance about Activity Based Learning was available to them.

2. Fifty percent of PSTs replied that DTEs much guidance about Activity Based Learning was available to them.

3. Four percent of PSTs replied that DTEs less guidance about Activity Based Learning was available to them.

4. None percent of PSTs replied that DTEs very less guidance about Activity Based Learning was available to them.

5. Two percents of PSTs replied that DTEs no guidance about Activity Based Learning was available to them. 


\section{Area No.4 Use of support material}

\section{Availability of A.V. Aids in class room}

1. Eight percent of PSTs replied that they had found very much availability of A.V. Aids in class room.

2. Thirty-three percent of PSTs replied that they had found much availability of A.V. Aids in class room.

3. Thirty-three percent of PSTs replied that they had found less availability of A.V. Aids in class room.

4. Eleven percent of PSTs replied that they had found very less availability of A.V. Aids in class room.

5. Fifteen percent of PSTs replied that they had not found availability of A.V. Aids in class room

\section{Area No. 5 Interaction with students}

\section{DTEs guidance about skillful interaction with students}

1. Twenty-seven percent of PSTs replied that they had found DTEs very much guidance about Skillful Interaction with Students.

2. Sixty percent of PSTs replied that they had found DTEs much guidance about Skillful Interaction with Students was available to them.

3. Ten percent of PSTs replied that they had found DTEs less guidance about Skillful Interaction with Students was available to them.

4. Two percent of PSTs replied that they had found DTEs very less guidance about Skillful Interaction with Students was available to them.

5. One percent of PSTs replied that they had not found DTEs guidance about Skillful Interaction with Students. 


\section{Area No.6 Management of class room}

\section{Availability of DTEs guidance about class room management technique}

1. Forty-four percent of PSTs replied that they had found DTEs very much guidance about class room management techniques.

2. Fifty-one percent of PSTs replied that they had found DTEs much guidance about class room management techniques.

3. Two percent of PSTs replied that DTEs less guidance about class room management techniques was available to them.

4. None percent of PSTs replied that DTEs very less guidance about class room management techniques was available to them.

5. Three percent of PSTs replied that DTEs guidance about class room management techniques was not available to them.

\section{Area No. 7 Student assessment}

\section{Availability of DTEs guidance about student's assessment}

1. Thirty-five percent of PSTs replied that they had found DTEs very much guidance about student's assessment.

2. Fifty-seven percent of PSTs replied that they had found DTEs much guidance about student's assessment.

3. Six percent of PSTs replied that they had found DTEs less guidance about student assessment.

4. None percent of PSTs replied that they had found DTEs very less guidance about student's assessment.

5. Two percent of PSTs replied that DTEs guidance about student's assessment was not available to them.

\section{Area No. 8 Home work for students}

\section{Availability of DTEs guidance about the assignment of appropriate home work for students}

1. Thirty-six percent of PSTs replied that DTEs very much guidance about the assignment of appropriate home work for students was available to them. 
2. Fifty-seven percent of PSTs replied that DTEs much guidance about the assignment of appropriate home work for students was available to them.

3. Five percent of PSTs replied that DTEs less guidance about the assignment of appropriate home work for students was available to them.

4. Two percent of PSTs replied that DTEs very less guidance about the assignment of appropriate home work for students was available to them.

5. None percent of PSTs replied that DTEs guidance about the assignment of appropriate home work was not available to them.

Major findings indicated that Primary School Teachers (PSTs) were found satisfied about the District Teacher Educators mentoring programme. Primary School Teachers were satisfied in all areas of mentoring support programme.

However, PSTs were not found satisfied about the availability of revised Ta'leemi Calendar and the effectiveness of lesson plan in view of its local requirement.

\section{Findings}

Phase II

\section{Cluster Training and Support Centre Heads' responses about the impact of DTEs mentoring programme}

Findings of the CTSC Heads responses about DTEs mentoring programme have been given item-wise, respectively, as under:

\section{Item1}

Satisfaction about the effectiveness of mentoral programme for PSTs professional development

1. Ten percent of CTSC Heads reported that they were very much satisfied with the effectiveness of mentoral programme of PSTs professional development.

2. Thirty percent of CTSC Heads reported that they were much satisfied with the effectiveness of mentoral programme of PSTs professional development. 
3. Thirty three percent of CTSC Heads reported that they were less satisfied with the effectiveness of mentoral Programme of PSTs Professional development.

4. Fifteen percent of CTSC Heads reported that they were very less satisfied with the effectiveness of mentoral programme of PSTs professional development.

5. Twelve percent of CTSC Heads reported that they were not satisfied with the effectiveness of mentoral programme of PSTs professional development.

Overall analysis of findings pertinent to this item showed that 40 percent of CTSC Heads were found satisfied and 60 percent of CTSC Heads were not found satisfied with the effectiveness of mentoral programme of PSTs professional development.

\section{Item2}

\section{Increase in PSTs professional development through mentoral support promramme}

1. Six percent of CTSC Heads reported that PSTs had found very much increase in their professional development through mentoral support programme.

2. Twenty five percent of CTSC Heads reported that PSTs had found much increase in their professional development through mentoral support programme.

3. Fifty percent of CTSC Heads reported that PSTs had found less increase in their professional development through mentoral support programme.

4. Nineteen percent of CTSC Heads reported that PSTs had found very less increase in their professional development through mentoral support programme.

5. Seven percent of CTSC Heads reported that PSTs had not found any increase in their professional development through mentoral support programme.

Overall analysis of findings pertinent to this item indicated that 31 per-cents of CTSC Heads were satisfied and 69 percent of CTSC Heads were not satisfied with the increase in PSTs professional development through mentoral support programme. 


\section{Item3}

\section{Satisfaction about DTEs professional performance}

1. Ten percent of CTSC Heads perceived that they were very much satisfied with the DTEs professional performance.

2. Thirty-seven percent of CTSC Heads perceived that were they much satisfied with the DTEs professional performance.

3. Thirty five percent of CTSC Heads perceived that they were less satisfied with the DTEs professional performance.

4. Eight percent of CTSC Heads perceived that they were very less satisfied with the DTEs professional performance.

5. Ten percent of CTSC Heads perceived that they were not satisfied with the DTEs professional performance.

Overall analysis of findings pertinent to this item indicated that 47 percent of CTSC Heads were satisfied and 53 percent of CTSC Heads were not satisfied with the DTEs professional performance.

\section{Item4}

\section{Perception about Overall standard of DSD's current mentoral programme}

1. Fifteen percent of CTSC Heads rated it as the best;

2. Twenty percent of CTSC Heads rated it as the better;

3. $\quad$ Fifty five percent of CTSC Heads rated it as the good / fair;

4. Ten percent of CTSC Heads rated it as the weak;

Overall analysis of findings pertinent to this item showed that 65 percent of CTSC Heads were satisfied and 35 percent of CTSC Heads were not found satisfied with the overall standard of DSD's mentoral programme. 


\section{Discussion}

\section{Phase I}

\section{Area No.1. Ta'leemi Calendar.}

The availability of Ta'leemi Calendar, the availability of guidance about the use of Ta'leemi calendar, the usage of Ta'leemi Calendar during teaching and the improvement in PSTs professional skill by the use of Ta'leemi Calendar was all found desirably positive while the availability of revised Ta'leemi Calendar was not found according to the required demand, in this area. Its reasons might be speculated as the lack of funding for revised publications, delayed publications of revised Ta'leemi Calendar, lack of proper supply system or lack of DTEs proper follow-up for supply of revised Ta'leemi Calendar.

\section{Area No.2. Lesson Plan.}

The results indicated that the availability of lesson plan, DTEs guidance about the preparation of lesson plan, the improvement in teaching process through usage of lesson plan, and the improvement in professional skill through usage of lesson plan were all found desirably positive. While, the effectiveness of lesson plan in view of its local requirement was found comparatively at lower rank. It might have occurred due to incompetent or less qualified teachers or due to DTEs less skill in providing the guidance for this task.

\section{Area No.3. Activity Based Teaching and Learning.}

The results indicated that the DTEs guidance about Activity Based Teaching and Learning, the usage of stories and examples in teaching process, the usage of the Activity Based Teaching and Learning method and the improvement in professional skill through usage of activities in teaching were all found desirably positive. While, the satisfaction about the activities given in Basic Foundation Module (BFM) was found comparatively at lower level in this area. Its reason might be speculated as some teachers would be incompetent / less qualified, or Basic Foundation Module (BFM) activities themselves might be very tough for such teachers, or such activities might be mismatched with the local culture at particular places.

\section{Area No. 4. Use of Support Material.}

The results showed that the DTEs guidance about the preparation and the usage of low cost material, the usage of A.V. Aids during teaching process, the improvement of teaching process through usage of A.V. Aids and the improvement of professional skill through usage of 
A.V. Aids were all found desirably positive while, the availability of A.V. Aids in class room was not found according to the required demand. Its reason might be lack of funding for supply of A.V. Aids, lack of proper supply system, lack of DTEs proper follow up for the supply of A.V. Aids in class-room or over-burdened teaching work in single teacher schools. 
Area No. 5. Interaction with Students.

The results showed that the DTEs guidance about skillful interaction with students, the effectiveness of teaching process in the light of DTEs guidance, the improvement in students' performance through teachers increased interaction with them, and the improvement in teachers' professional skill through interaction with students were all found desirably positive. While, the skill improvement for interaction with students in large classes was found comparatively at lower level. Its reason might be lack of discipline management, less skillful teachers, lack of proper environment, or lack of DTEs guidance about interaction with students in large classes and discipline management.

\section{Area No.6. Management of Class Room.}

The results showed that the availability of DTEs guidance about class room management techniques, the improvement in class management through DTEs guidance, the improvement in teaching process through better class-room management and the increase in professional skill through class-room management were all found desirably positive. While, the success in specific management for specific class-room activities was found comparatively at lower level. Its reason might be lack of specific-activities oriented teaching, lack of DTEs guidance for specific management, lack of the PSTs interest about teaching techniques.

\section{Area No.7. Students’ Assessment.}

The results showed that the availability of DTEs guidance about students' assessment, the teacher practice about the assessment of students' performance, the increase in students' performance, the increase in students' performance through students' assessment and the increase in professional skill through students' assessment were all found desirably positive. While, the availability of DTEs guidance about testitem development techniques was found comparatively at lower level. Its reason might be lack of DTEs proper training for test item development, less focus on test-item development and reliance upon market-based testitems or model test papers, etc.

\section{Area No. 8. Home Work for Students.}

The results showed that the availability of DTEs guidance about the assignment of appropriate home work for students, the practice of regular checking of students' home work, the increase in students' performance through home work, and the improvement in professional skill through checking of students' home work were all found desirably positive. While, the practice of regular error correction during home 
work checking was found comparatively weaker. Its reason might be lack of PSTs proper interest for checking the home work, lack of DTEs guidance about home work, over burdened teaching work in single teacher schools.

\section{Discussion}

Phase II.

Item 1 to 4

Discussion of CTSC Heads responses about DTEs mentoring programme has been given as under:

The review of CTSC Heads perceptions as reflected in the findings indicated that the overall standard of DSD's ongoing mentoral programme was desirably positive. While, CTSC Heads satisfaction about the expected effectiveness of mentoral programme, the expected increase in PSTs professional development, the expected professional performance of DTEs were all found comparatively at lower level. The CTSC Heads have not been found satisfied with the expected achievements in these areas. Its reasons might be speculated as:

1. The weak co-ordination, and interaction between CTSC Heads and DTEs;

2. The weak co-ordination and interaction between CTSC Heads and Mentees;

3. The weak co-ordination and interaction between CTSC Heads and DSD's management;

4. The lack of deep interest among DTEs about the uplift of mentoral support programme;

5. The weak management in the implementation of mentoral support programme at CTSC level;

6. The shortage of funding and facilities at CTSC level required for full-fledged launch of this programme.

Moreover, it might be the presence of less qualified PSTs, the appointment of less qualified DTEs, the severe deficiency of teaching staff in schools, and the lack of specifically mentoring oriented promotion structure for DTEs. 


\section{Conclusion}

\section{Phase I}

Conclusions reached through review of the findings of Mentees Responses were as under:

1. The impact of DTEs mentoral support upon Mentees follow-up of Ta'leemi Calendar has been found reasonably positive while, this impact has been noted comparatively weaker in the availability of revised Ta'leemi Calendar.

2. The impact of DTEs mentoral support upon Mentees skill for the preparation of lesson plan was analyzed as reasonably positive according to the mentees own responses. This impact has been noted less dominant and comparatively weaker in the particular aspect of the lesson plan effectiveness for the local requirement.

3. The impact of DTEs mentoral support upon Mentess involvement in activity based teaching and learning was investigated reasonably positive according to mentees own responses. This impact has been noted less dominant and comparatively weaker in the satisfaction about the activities given in Basic Foundation Module.

4. The impact of DTEs mentoral support upon mentees skill in the use of support material was found out reasonably positive according to mentees own responses. While this impact has been noted less dominant and comparatively weaker in the availability of A.V. Aids in class-room.

5. The impact of DTEs mentoral support upon Mentees interaction with the students was determined reasonably positive according to mentees own responses. This impact has been noted less dominant and comparatively weaker in the teachers' skill improvement for interaction with students in large classes.

6. The impact of DTEs mentoral support upon Mentees skill in the area of class-room management has been analyzed as reasonably positive according to mentees own responses. This impact has been noted less dominant and comparatively weaker in the specific management for specific class-room activities.

7. The impact of DTEs mentoral support upon Mentees skill for students assessment was also ranked as reasonably positive according to mentees own responses. This impact has been noted less dominant and comparatively weaker in the availability of DTEs guidance about test item development techniques.

8. The impact of DTEs mentoral support upon Mentees skill to assign meaningful homework to students was found reasonably positive according to mentees own responses. This impact was noted less 
dominant and comparatively weaker in the practice of regular error correction on daily basis during home work checking.

\section{Conclusion}

\section{Phase II}

Conclusions reached through review of the findings of CTSC Heads response are as under:

\section{Item1}

Overall analysis of findings pertinent to this item indicated that $40 \%$ of CTSC Heads were satisfied and $60 \%$ of CTSC Heads were not satisfied with the effectiveness of mentoral programme of PSTs professional development.

Thus, it can be concluded that the majority of CTSC Heads was not satisfied about the effectiveness of mentoral program of PSTs professional development.

\section{Item 2}

Overall analysis of findings pertinent to this item indicated that $31 \%$ of CTSC Heads were satisfied and $69 \%$ of CTSC Heads were not satisfied with the increase in PSTs professional development through mentoral support programme.

Thus, it also gives the conclusion that only one third numbers of CTSC Heads had found good rate of program in professional skill of PSTs.

Item 3

Overall analysis of findings pertinent to this item indicated that $47 \%$ of CTSC Heads were satisfied and 53\% of CTSC Heads were not satisfied with the DTEs professional performance.

It concludes that CTSC Heads satisfaction with the performance of DTEs was on average level. 


\section{Item 4}

Overall analysis of findings pertinent to this item indicated that $65 \%$ of CTSC Heads were satisfied and 35\% of CTSC Heads were not satisfied with the overall standard of DSD's mentoral programme.

It shows that overall standard of DSD's current mentoral programme was above average level.

\section{Recommendations}

1. Revised Ta'leemi Calendar should be provided to all PSTs on regular basis.

2. Lesson plans should be made effective and relevant to the local requirement of students.

3. Activities given in Basic Foundation Module (BFM) should be revised. They should be motivational and interesting for the mentees.

4. A.V.Aids should be made available in the class-rooms. They should be used in the class-rooms. A.V. Aids should be arranged properly and meaningfully in the class room for all students.

5. Teachers should be provided skill and training for interaction with students in large classes.

6. Specific training should be imparted to the mentees during management of class rooms for the conduct of specific activities.

7. DTEs guidance about test item development techniques should be imparted to all PSTs.

8. Practice of regular error correction should be made permanent during home work checking.

9. Effectiveness of mentoral programme for PSTs professional development should be made significant.

10. PSTs professional development through mentoral support programme should be continuously increased. It should not be stopped at any time.

11. DTEs should provide exact information to their CTSC Heads about the updates and betterments related to the Mentees (PSTs) professional development and their own professional performance on regular basis. 


\section{References}

Corsini, R.J. (Ed.). (1987). Concise encyclopedia of Psychology. Canada: John Wiley \& Sons, Inc.

Directorate of staff Development.(2007). A guide for District Teacher Educators and Heads of Cluster Training and Support Centre. Lahore: Quality Assurance, Monitoring \& Evaluation Wing, DSD.

Khawaja, S. (2001).Evaluation and monitoring. Islamabad: Mr. Books.

Ladd, $\mathrm{H}$.(2007). Teacher supply and demand-developed countries.The future of children, 17 (1), 201-217.Retrieved Nov 1, 2011 from muse. The edu/ Journals/ foc/summary vol 17.1 add html.

Mandi Baha-ul-Din District (M.B.Din.) (2010). Pakistani Cities.Retrieved July 7, 2012, from http:// Pakistani-Cities, Blog Spot. Com./, Mandi Baha-ulDin-history of mandi.html.

Mertens, D.M. (2010). Research and evaluation in education and psychology. London: Sage.

Messurier, M.L. (2012). An in-school mentoring programme for students. Retrieved September 2,2012, from http: /Marklemessurier com. $\mathrm{Au} / \mathrm{main} /$ mentoring html.

Paris, L. (2010).Reciprocal mentoring residencies better training to teaching.Australian Journal of Teacher Education, 35(3) 14.

Rossi, P.H. (2004). My views of evaluation and their origins. In M.C. Alkin (Ed.)., Evaluation roots ( pp. 122-131). California: Sage Publishers, Inc.

Saeed, M. (2000) .Intial and in- service training of school teachers in F.R. Germany., France and U.K.Amozish 1(1), 84-99

Shukla, R. (2005). Dictionary of education. New Delhi: Publishing Corporation.

Received on: February 28, 2016

Revised on: May 25, 2016

Accepted on: June 02, 2016 